\title{
USE OF SOCIAL MEDIA AND ACADEMIC PERFORMANCE OF STUDENTS: EVIDENCE FROM UNDERGRADUATE STUDENTS IN UNIVERSITY OF JAFFNA, SRI LANKA
}

\author{
Jeyan Suganya. D.F \\ Department of Financial Management \\ University of Jaffna, Sri Lanka \\ L. Kengatharan \\ Department of Financial Management \\ University of Jaffna, Sri Lanka \\ lingesiya@univ.jfn.ac.lk

\section{R. Yogendrarajah} \\ Department of Financial Management \\ University of Jaffna, Sri Lanka
}

\begin{abstract}
This study attempts to examine the impact of use of social media on academic performance of students. Primary data was collected from sample of hundred and eighty students who were following degree of Bachelor of Business Administration programme in faculty of management studies and commerce, University of Jaffna from first year to final year. Use of social media is measured using different dimensions such as time duration, addictiveness, exposure and nature of usage, while overall Grade Point Average is used to measure academic performance of the students issuing structured questionnaires. Descriptive statistics, correlation analysis, multiple regression analysis and ANOVA test were employed to analyse collected data for the study. Result revealed that time duration in use of social media and addictiveness to social media have significant negative impact on academic performance of students, however, exposure to social media and nature of usage don't have any significant impact on academic performance of students. Further, it was found that there is no significant difference in using hours of social media for educational and non-educational purpose among the students studying in different years. Finding of the study may lead the students to manage their valuable time spending in social media without negatively impact on their academic performance.
\end{abstract}


The students may be encouraged to enhance their academic performance by using social media much more for educational purpose.

Keywords: Academic performance; Addictiveness; Exposure; Social media; Time duration

\section{Introduction}

Social media is becoming a dominant part of many people's life today, since it is considered as a faster approach to know about anything they need at any time. It seems to play an imperative role in each sector around the world since use of it leads to have new information in several ways. It is growing tremendously in few years and considered as one of the most acceptable reasons behind globalization. Social media refers to computer programs and various websites that let the people to communicate and share information on the internet using electronic devices. So many social media platforms have been introduced until now like face book, Google + , twitter, WhatsApp, Instagram, Skype, Viber, LinkedIn and YouTube. It is utilized by different individual and organisations such as students, parents, academics, business people, politicians, researchers and religious organisations in many forms for different reasons. Most of the young people use it at higher percentage for their educational and non-educational purpose as found in the previous result of the researches. Uses of social media vary country to country since it requires stipulated infrastructures, tools and techniques for using without any interruption. Modernised equipment and techniques are utilized in developed countries for improving social media network, however only most essential tools are used in developing countries for introducing use of social media since they have higher number of remote villages without even any electricity facilities.

User of social media may be benefited with positive impact on their goal as well as be affected with negative impact. The main advantage of social media enjoyed by many people is enhancing connectivity which means people from anywhere can communicate with the people accommodated in any place in the world. It helps business people and organisation to promote their product to the largest audience groups and thereby reputation of the business will be increased. Any people can able to update themselves with the recent information in the world. It gives a wonderful opportunity to the students and academics to enhance their knowledge with the help of different method of providing education without paying for it. It is an innovative way 
for government to maximize awareness and citizen engagement since it is an efficient and low cost distribution channel for sharing public information. It is considered as the best entertainment provider to the people who are in any category such as children may enjoy the games, young adults may prefer new films and music while old people may get pleasure from television programmes like dramas. Even though too many benefits are expected from the use of social media, unfortunately, it leads to certain percentage of disadvantages to the people. Personal data and privacy may be hacked and shared on the Internet and it can lead to financial losses and be used to lose an individual life. Most of the teenage people are addicted to the use of social media; therefore they lose their education and productive life in the future. People may be inspired by others to drugs and alcohol introduced by other communities in the social media. One of the most identified disadvantage of using social media is health issues such as depression, anxiety, sleeplessness, eating issues, vision problem and increased suicide risk. Therefore, most of the scholars are interested to carry out the research to clear the questions in the mind of stakeholders of social media.

\section{Statement of the Problem}

Numbers of internet users are increasing continuously year by year. According to the Singh (2017), there were 6.5 billion Internet users around the world and in 2014 it became 7.2 billion in 2015 since it has considerable impact on each and every sector including education of the students. Most of the parents are worrying that their children are spending much time with social media. It may affect educational performance of their students. However, students may think that they may update their recent knowledge quickly rather going through and referring published books later. It leads to enhance the general knowledge and various research findings related to their field in other countries. Therefore, impact of use of social media on academic performance among higher education students is considered as highly debated topic among most of the stakeholders.

Therefore, so many studies have conducted to investigate to what extent use of social media impact on usual life of the people. This study intends to examine how far usage of social media impact on academic performance of undergraduate students. It is analysed with the data collected from the undergraduate students who are studying in faculty of management studies and commerce, University of Jaffna in 2018.

Journal of Business Studies, 7(2)

$-64-$

2020 


\section{Review of Literature}

The major theory behind this study is social constructivism theory. It is a sociological theory of learning and knowledge proposed by Vygotsky (1978). The major theme of social constructivism theory is human learning and knowledge is constructed through social and cultural interaction. It gives an idea that people can learn with the assistance of other people who have the knowledge on the particular aspect, which means people can learn and enhance their knowledge by using social media to gather more ideas and knowledge with more information provided by people who are living in different part of the world on the various websites. However, social media is used by the students not only for educational purpose but also for non-educational purpose specifically for their entertainment. Therefore, this study analyses whether both educational and noneducational usage of social media impact academic performance of the undergraduate students.

Another theory developed by Bulmer and Katz in 1974 called Uses and Gratifications theory says that users of media play an active role in choosing and using the media to best fulfil their needs and gratifications. They have the power and responsible to interact their own life with social media. It assumes the audience use social media mainly for five different reasons such as information and education, entertainment, personal identity, integration and social interaction and escapism.

Under the above theories, many studies discussed how use of social media impact on academic performance of students in various method and statistical analysis for finding clear solution and encouraging and motivating the students in the acceptable way. Few studies were conducted in Sri Lanka to test how far use of social media impact on academic performance of students. Melani and Andrew (2017) have carried out a study to examine the influence of Social Media on Academic Performance of students following Bachelor of Business Administration programme in Eastern university of Sri Lanka. They found that use of social media has significant influence on academic performance of the students employed Chi-square analysis and further recommended students should be encouraged to use social media for educational purpose. Thuseethan and Kuhanesan (2014) intended to examine the impact of use of face book on university students' academic performance by issuing questionnaire to 250 students studying in different universities located in Sri Lanka. They revealed that frequent users of face book got low GPA than the students used it rarely. 
Mensah and Nizam (2016) attempted to investigate the impact of social media on academic performance of the students studying in Tertiary Institution, Malaysia. They identified that time appropriateness had significant negative impact while relationship between friends and people connection, nature of usage and health addiction had significant positive impact on academic performance of students. However, time duration and privacy problem did not have any significant impact on students' academic performance.

Talaue et al. (2018) intended to analyse the impact of social media on academic performance of selected college students. Only sixty students who were specialized in business administration and management information system have been selected as the sample of the study. Researchers have mainly used descriptive analysis to find their solution of the research. It was found that usage of social media negatively impacts on academic performance of the students due to the time spent on social media stressed them.

Inverse relationship of use of social media with academic performance of the students was by Hasnain et al., (2015) in Pakistan. Further, researcher said that when social media is used in positive manner, it leads the students to enhance their knowledge and academic performance. Another study done in United States of America by Junco (2015) to analyse impact of Student class standing and Face book use on academic performance. Researcher found that found that time spent on face book by senior students were significantly less than junior students and there was a negative relationship of time spent on Face book with overall GPA of the junior students.

Boogart (2006) was selected four famous Universities in United States of America to conduct a study with 3134 students as respondents and found that females students spent much time on face book than male students and the students who had lower GPA spent more time on face book than the students with higher GPA. Therefore, negative relationship was found between time spent on face book and academic performance of the students. Emeka and Nyeche (2016) exposed that use of internet for educational purpose enhance undergraduate students' skills, knowledge and capability to improve their professional life in future with the help of their study done among the students studying in University of Abuja, Nigeria.

Positive impact of growing use of social media on the academic performance was found by Zahid, et al., (2016) with the study of 300 students of the various universities 
and colleges in Pakistan. Celestine and Nonyelum (2018) tried to assess the impact of social media sites on student academic performance in Samuel Adegboyega University, Nigeria using descriptive survey. The result of the study showed that there is significant relationship between time spent on social media sites and academic works. Further, it was revealed that the nature of social media activities and gender do not have any significant impact on the student academic performance.

\section{Formulation of Hypotheses}

Hypotheses are formulated based on the findings from previous research carried out in various countries as follows:

\subsection{Addictiveness to Social Media on Academic Performance}

Addictiveness to social media refers to mental distress over the use of social networks and spending more time in these networks, it affects other social activities of individual like education and profession (Andreassen and Pallesen, 2014). Ndubuaku et al., (2020); Azizi (2019) and Stankovska et al., (2016) found negative relationship between students' addiction to social networking and their academic performance. Male students were addicted higher level compared to the female students. Further, It was identified that social media addiction has a positive association with depression of students (Haand and Shuwang, 2020).

$H 1$ : There is a significant impact of addictiveness to social media on academic performance of the undergraduate students

\subsection{Exposure to Social Media on Academic Performance}

Exposure to social media has been increased among the students since production and distribution of sophisticated mobile phones influence them and it complicated the situation as they no longer need to visit a cyber cafe to communicate globally (Peter, 2015). It was revealed that there was a significant influence of exposure to social media on academic performance of students (Peter, 2015; Kolan and Dzandza, 2018). $H 2$ :There is a significant impact of exposure to social media on academic performance of the undergraduate students

\subsection{Time Duration of the Use of Social Media on Academic Performance}

Reynol and Junco (2012) identified that time spent to check face book adversely affect academic performance of the students in their study. Because it affects the time used for study. The studies done by Paul et al., (2012) and Kirschner and Karpinski 
(2010) found that the students who spent more time on social networking shows adverse academic performance.

$H 3$ : There is a significant impact of time duration of the use of social media on academic performance of the undergraduate students

\subsection{Nature of usage of Social Media on Academic Performance}

Positive and significant association was found between nature of usage of social media and students' academic performance in the studies done by Mensah \& Nizam (2016). Further, they states that students are attracted to join to interesting groups globally with social networking, which allows them to learn new skills in the relevant areas as their wishes.

H4: There is a significant impact of nature of usage of social media on academic performance of the undergraduate students

\subsection{Difference in Using Hours of Social Media for Educational and Non-educational Purpose Among the Students Studying in Different Years}

Students who are studying in fourth year spend more time in social media to get the information for preparing research articles and thesis compared to first year students. Peter (2015) ascertained that there is a significant difference in usages of social media network by the students in different age.

H5: There is a significant difference in using hours of social media for educational and non-educational purpose among the students studying in different years

\section{Methodology}

The sample of the study was derived from the population of the students who were following Degree of Bachelor of Business Administration in Faculty of management studies and commerce, University of Jaffna in 2018. Primary data was collected using standard questionnaire with 5 point likert-scale used in the study done by Peter (2016) from randomly selected one hundred and eighty (180) students from first year to fourth year in four departments such as department of accounting, department of financial management, department of human resource management and department of marketing during their second semester study programme. Uses of social media is measured under four independent variables of time duration, addictiveness, exposure, and nature of usage (Peter, 2016) while academic performance of the students is measured using GPA point (Azizi et al., 2019) of each respondents in the study. 
Descriptive statistics, reliability test, correlation and regression analysis and ANOVA test are employed to test hypothesis of the study. Regression model of the study is as follows:

$\mathrm{APS}=\alpha+\beta 1 \mathrm{TD}+\beta 2 \mathrm{ADD}+\beta 3 \mathrm{EXP}+\beta 4 \mathrm{NOU}+$

Where:

$\begin{array}{lll}\text { APS } & = & \text { Academic performance of the students } \\ \mathrm{TD} & = & \text { Time duration of uses of social media } \\ \mathrm{ADD} & = & \text { Addictiveness to social media } \\ \mathrm{EXP} & = & \text { Exposure to social media } \\ \text { NOU } & = & \text { Nature of usage of social media }\end{array}$

\section{Data Analysis and Discussion}

Descriptive and inferential statistics have been employed in the analysis of this study to make conclusion by testing formulated hypothesis.

\subsection{Demographic Characteristics of Respondents}

Data has been collected from hundred and eighty students who are following Degree

Table 1: Demographic Characteristics of Respondents

\begin{tabular}{|c|c|c|c|}
\hline Variable & Values & Frequency & Percentage \\
\hline \multirow{2}{*}{ Gender } & Male & 90 & $50 \%$ \\
\hline & Female & 90 & $50 \%$ \\
\hline \multirow{4}{*}{ Year of the student } & First year & 45 & $25 \%$ \\
\hline & Second year & 45 & $25 \%$ \\
\hline & Third year & 45 & $25 \%$ \\
\hline & Fourth year & 45 & $25 \%$ \\
\hline \multirow{3}{*}{ Ethnic group of the student } & Tamil & 85 & $47 \%$ \\
\hline & Sinhala & 75 & $42 \%$ \\
\hline & Muslim & 20 & $11 \%$ \\
\hline \multirow{5}{*}{$\begin{array}{l}\text { Most frequently using social } \\
\text { media }\end{array}$} & Face book & 92 & $51 \%$ \\
\hline & Viber & 64 & $36 \%$ \\
\hline & WhatsApp & 15 & $8 \%$ \\
\hline & Twitter & 6 & $3 \%$ \\
\hline & Wikipedia & 3 & $2 \%$ \\
\hline
\end{tabular}

Journal of Business Studies, 7(2)

$-69-$

2020 
Equal number of males and females were selected randomly among the students from first year to final year and $25 \%$ of sample was taken from each year of the students. Most of the students studying in university of Jaffna are from Tamil ethnic groups as it is located in Jaffna while Muslim students are very less. More than half percentage of sample students are using face book most frequently than other media as it is provided higher facilities to keep contact with friends and relatives. First year and second year students are following common programme and then they are divided in to four departments since third year. Therefore, department wise information was not received from respondents.

\subsection{Reliability Test}

Lee Cronbach in 1951 developed the test called Cronbach's Alpha test to measure reliability and validity of data. It ensures that to determine whether the instrument used in the study are valid and reliable. When the value of Cronbach's Alpha is higher than 0.6 , it is considered as acceptable.

Table 2: Reliability Test

\begin{tabular}{lcc}
\hline \multicolumn{1}{c}{ Dimensions of variables } & No. of dimensions & Cronbach's Alpha $(\boldsymbol{\alpha})$ \\
\hline Time duration & 6 & 0.617 \\
Addictiveness & 6 & 0.655 \\
Exposure & 6 & 0.716 \\
Nature of usage & 6 & 0.871 \\
\hline
\end{tabular}

In order to measure each independent variable of the study, six relevant questions under each were given to the respondents. According to the standard, value of cronbach's alpha for each variable is higher than 0.6. it is found that all of the measures are reliable for analysis.

\subsection{Descriptive Analysis}

It is a basic statistical analysis provides central tendency of data and allows to carry out further analysis for the study. It presents minimum, maximum, mean and standard deviation of data separately for each independent and dependent variable. 


\section{Table 3: Descriptive Statistics}

N Minimum Maximum Mean Std.

Deviation

\begin{tabular}{llllll}
\hline Time duration & 180 & 1.50 & 4.50 & 2.3250 & 0.46756 \\
Addictiveness & 180 & 1.00 & 5.00 & 2.9250 & 0.70952 \\
Exposure & 180 & 1.40 & 4.60 & 3.0289 & 0.68017 \\
Nature of usage & 180 & 1.20 & 5.00 & 3.2800 & 0.67736 \\
Academic Performance of the & 180 & 1.29 & 3.93 & 2.9448 & 0.63772 \\
Students & & & & \\
\hline Valid N (listwise) & 180 & & & \\
\hline
\end{tabular}

According to the table 3, Most of the students are spending their time in social media below average as mean of time duration is 2.325 . However, means of addictiveness, exposure and nature of usage are above 2.5. It says that most of the students are addicted to social media, exposure to social media is high and use of social media for non-educational purpose is also at high percentage than purpose of educational use. More number of student respondents are near to second class lower division. Standard deviation shows that there is no any extreme value or outlier in the data since the value is very low for each variables.

\subsection{Correlation Analysis}

Correlation analysis measures strength of relationship between two variables but not cause and effect relationship. It shows relationship of time duration, addictiveness, exposure and nature of usage with academic performance of the students

Table 4 : Correlation Analysis

\begin{tabular}{llccccc}
\hline & & TD & ADD & EXP & NOU & APS \\
\hline \multirow{2}{*}{ TD } & Pearson Correlation & 1 & & & & \\
& Sig. (2-tailed) & & & & & \\
\hline \multirow{2}{*}{ ADD } & Pearson Correlation & .125 & 1 & & & \\
& Sig. (2-tailed) & .093 & & & & \\
\hline \multirow{2}{*}{ EXP } & Pearson Correlation & .035 & $.426^{* *}$ & 1 & & \\
& Sig. (2-tailed) & .641 & .000 & & & \\
\hline \multirow{2}{*}{ NOU } & Pearson Correlation & .031 & $.395^{* *}$ & $.621^{* *}$ & & \\
& Sig. (2-tailed) & .679 & .000 & .000 & & \\
\hline \multirow{2}{*}{ APS } & Pearson Correlation & $-.243^{* *}$ & $-.293^{* *}$ & $-.205^{* *}$ & $-.166^{*}$ & \\
& Sig. (2-tailed) & .001 & .000 & .006 & .026 & \\
\hline$* *$ Correlation is significant at the 0.01 level (2-tailed). & & & \\
\hline$*$. Correlation is significant at the 0.05 level (2-tailed). & & & \\
\hline
\end{tabular}

Journal of Business Studies, 7(2)

$-71-$ 
Table 4 presents that there is a significant negative relationship of time duration $(\mathrm{r}=-$ $0.243, \mathrm{p}<0.01)$, addictiveness $(\mathrm{r}=-0.293, \mathrm{p}<0.01)$ and exposure $(\mathrm{r}=-0.205, \mathrm{p}<0.01)$ with academic performance of the students at $99 \%$ of confidence level. There is a significant negative relationship between nature of usage $(r=-0.166, p<0.05)$ and academic performance of the students at $95 \%$ of confidence level. All independent variables have significant week negative relationship with academic performance of the students.

\subsection{Multiple Regression Analysis}

Multiple regression analysis is used to predict magnitude of a dependent variable based on the level of more than one independent variables. It is used to test hypotheses of the study.

Table 5: Multiple Regression Analysis

\begin{tabular}{lcrrrr}
\hline \multicolumn{1}{c}{ Model } & \multicolumn{2}{c}{ Unstandardized } & \multicolumn{2}{c}{$\begin{array}{c}\text { Standardized } \\
\text { Coefficients }\end{array}$} & \multicolumn{2}{c}{ Coefficients } & T & Sig. \\
& B & Std. Error & \multicolumn{1}{c}{ Beta } & & \\
\hline (Constant) & 4.050 & .258 & & 15.697 & .000 \\
TD & -.092 & .031 & -.212 & -2.990 & .003 \\
ADD & -.199 & .071 & -.221 & -2.783 & .006 \\
EXP & -.089 & .087 & -.095 & -1.027 & .306 \\
NOU & -.012 & .086 & -.013 & -.141 & .888 \\
\hline
\end{tabular}

Dependent Variable: Academic Performance of the students

$\begin{array}{llll}R^{2}=.138 \quad \text { Adj. } R^{2}=.118 & F=7.000 & P(F \text { Statistic })=0.000\end{array}$

Result of multiple regression analysis in table 5 shows that value of adjusted $\mathrm{R}$ square is 0.118 , which means $11.8 \%$ of total variance in academic performance of the students is explained by all independent variables used in this study to measure use of social media. Model used for the study is found as appropriate and significant with the value of $\mathrm{p}<0.05$. Time duration $(\beta=-0.092, \mathrm{p}<0.01)$ and addictiveness $(\beta=-0.199, \mathrm{p}$ $<0.01$ ) have significant negative impact on academic performance of the students. Therefore, $\mathrm{H} 1$ and $\mathrm{H} 2$ are supported to these finding s of the study. Similar result was revealed by Azizi et al. (2019) and Kolan and Dzandza (2018) in their studies. However, exposure and nature of usage don't have any significant impact on academic performance of the students since $\mathrm{p}$ values are higher than 0.05 . Therefore, $\mathrm{H} 3$ and $\mathrm{H} 4$ are not supported to the findings of the study. This result consistent with the finding in the study done by Celestine and Nonyelum (2018) 


\subsection{ANOVAAnalysis}

Analysis of variance (ANOVA) is used to analyse the differences among group means in a sample. In order to examine whether there is a significant difference in using hours of social media for educational and non-educational purpose among the students studying in different years.

Table 6: ANOVA

\begin{tabular}{llrrrrr}
\hline & & \multicolumn{1}{c}{$\begin{array}{c}\text { Sum of } \\
\text { Squares }\end{array}$} & df & \multicolumn{1}{c}{$\begin{array}{c}\text { Mean } \\
\text { Square }\end{array}$} & F & Sig. \\
\hline Use of time for & Between Groups & 8.392 & 3 & 2.797 & 1.491 & .219 \\
educational & Within Groups & 330.294 & 176 & 1.877 & & \\
purpose & Total & 338.686 & 179 & & & \\
\hline Use of time for & Between Groups & 5.983 & 3 & 1.994 & .307 & .820 \\
non-educational & Within Groups & 1141.967 & 176 & 6.488 & & \\
purpose & Total & 1147.950 & 179 & & & \\
\hline
\end{tabular}

According to the result shows in table 6, It is found that there is no significant difference in using hours of social media for educational and non-educational purpose among the students studying in different years as $p$ values are not significant for use of time for educational and non-educational purpose respectively $p$ value $=0.219$ and 0.820 . Therefore, H5 states there is a significant difference in using hours of social media for educational and non-educational purpose among the students is not supported to the finding of the study.

\section{Conclusion}

This study intended to examine the impact of use of social media on academic performance of undergraduate students. Results of the study revealed that most of the students are addicted to the use of social media for the purpose of non-educational purpose and time they are spending in social media is increasing for entertainment activities rather educational activities. It consistent with findings of Nasrullah and Khan (2019), they confirmed that most of them strongly believe that all the information in social media is true and reliable, further, said that social media does not support to learning of the students.

Therefore, academic performance of most of the students measured using GPA is below average. If these situation is continued in future, they cannot be appointed in the higher position of any job required higher GPA with first and second class upper division. Organization are seeking broad skills including content creation, problem 
solving, information seeking skills, analytical skills, motivating others towards a positive thinking, networking skills, updating knowledge skills, and dissemination of knowledge. So the students should manage their time to enhance these skills to manage the future job market. Further, Students are advised to manage their valuable time spending in using social media mostly for educational purposes. However, social media can facilitate the students for sharing the knowledge among the students, sharing the study material, submitting the assignment and passing important information etc. We can simply share the videos via social medias. Therefore, it can be advised users to use the social media for certain needs can be befitted. Further studies should be conducted not only among undergraduate students but also among school students to motivate them towards better performance. Because, most of the learning activities are conducted via mobile phones for school students in this pandemic situations. 


\section{References:}

Andreassen, C.S. \& Pallesen, S. (2014). Social Network Site Addiction - An Overview. Current Pharmaceutical Design, 20(25), 4053-4061.

Azizi, S. M., Soroush, A., \& Khatony, A. (2019). The relationship between social networking addiction and academic performance in Iranian students of medical sciences: a cross-sectional study. BMC Psychology, 7(28), $2-8$.

Blumler Jay, G., \& Katz, E. (1974). eds., The Uses of Mass Communications: Current Perspectives on Gratifications Research. Sage Annual Reviews of Communication Research, 40 (1), 132-133.

Boogart, M. R. V. (2006). Uncovering the social impacts of Facebook on a college campus. Master's Thesis, Kansas State University, Manhattan, Kansas.

Celestine, A. U., \& Nonyelum, O. F. (2018). Impact of social media on students' academic performance. International Journal of Scientific \& Engineering Research, 9(3), 1454-1462.

Cronbach, L. J. (1951). Coefficient alpha and the internal structure of tests. Psychometrika, 16, 297-334.

Emeka, U. J., \& Nyeche, O. S. (2016). Impact of Internet Usage on the Academic Performance of Undergraduates Students: A case study of the University of Abuja, Nigeria. International Journal of Scientific \& Engineering Research, 7 (10), $1018-1029$.

Hasnain, H., Nasreen, A., \& Ijaz, H. (2015). Impact of social media usage on academic performance of university students. In 2nd International Research Management \& Innovation Conference (IRMIC), Research Management Centre, International Islamic University College Selangor (KUIS).

Junco, R. (2015). Student class standing, Facebook use, and academic performance. Journal of Applied Developmental Psychology, 36: 18-29.

Kolan, B. J., \& Dzandza, P. E. (2018). Effect of Social Media on Academic Performance of Students in Ghanaian Universities: A Case Study of University of Ghana, Legon. Library Philosophy and Practice (e-journal). 1637. https://digitalcommons.unl.edu/libphilprac/1637. 
Melani, A., \& Andrew, A. (2017). Social Media and Academic Performance of Undergraduate Students. International Journal of Research, 4 (4), 3449-3462.

Mensah, S. O., \& Nizam, I. (2016). The impact of social media on students' academic performance - A case of Malaysia Tertiary Institution. International Journal of Education, Learning and Training, 1(1), $14-21$.

Nasrullah, S., \& Khan, F. R. (2019). Examining the Impact of Social Media on the Academic Performances of Saudi Students-Case Study: Prince Sattam Bin Abdul Aziz University. Humanities \& Social Sciences Reviews, 7(5), 851-861

Ndubuaku, V., Inim, V., Ndudi, U. C., Samuel, U., \& Prince, A. I. (2020). Effect of Social Networking Technology Addiction on Academic Performance of University Students in Nigeria. International Journal of Recent Technology and Engineering, 8(5), 173-180.

Peter, O. (2016). Social Media and Academic Performance of Students in University of Lagos (Degree Dissertation, the University of Lagos) Retrieved from http://www.oresearchage.>publication

Reynol, J. (2012). Too much face and not enough books: The relationship between multiple indices of Face book use and academic performance. Computers in Human Behaviour, 28 (1), 187-198.

Singh, S. (2017). Importance and challenges of social media text. International Journal of Advanced Research in Computer Science, 8(3), 831-834.

Talaue, G. M., Alsaad, A.A., AlRushaidan, N., AlHugail, A., \& AlFahhad, S. (2018). the impact of social media on academic performance of selected college students. International Journal of Advanced Information Technology, 8 (4 \& 5), 27 -35.

Thuseethan, S., \& Kuhanesan, S. (2014). Influence of face book in academic performance of Sri Lankan University Students, Sabaragamuwa University of Sri Lanka, Sri Lanka. Global Journal of Computer Science and Technology: E Network, Web and Security, 14 (4), 29-35.

Vygotsky, L. S. (1978). Mind in Society: The Development of Higher Psychological Processes. Cambridge, MA: Harvard University Press.

Zahid, A., Ahmad, M., Syed, R. H., \& Faisal, H. (2016). Impact of Social Media of Student's Academic Performance. International Journal of Business and Management Invention, 5 (4), 22 -29. 